Int. J. Dev. Biol. 52: 999-1004 (2008)

doi: $10.1387 / \mathrm{ijdb} .082586 \mathrm{dc}$

\title{
Cloning and developmental expression of the soxB2 genes, sox 14 and sox21, during Xenopus laevis embryogenesis
}

\author{
DOREEN D. CUNNINGHAM, ZHUO MENG, BERND FRITZSCH ${ }^{1}$ and ELENA SILVA CASEY* \\ Georgetown University, Department of Biology, Washington DC and \\ ${ }^{1}$ Creighton University, Department of Biomedical Sciences, Omaha, NE, USA
}

\begin{abstract}
The Sox family of transcription factors is thought to regulate gene expression in a wide variety of developmental processes. Here we describe the cloning of the $X$. laevis orthologs of the SoxB2 family of transcription factors, sox14 and sox21. In situ hybridization revealed that sox 14 expression is restricted to the hypothalamus, dorsal thalamus, the optic tectum, a region of the somatic motornucleus in the midbrain and hindbrain, the vestibular nuclei in the hindbrain and a discrete ventral domain in the developing spinal cord. In contrast to the limited expression domain of sox 14, sox 21 is found throughout the developing central nervous system, including the olfactory placodes, with strongest expression at the boundary between the midbrain and hindbrain.
\end{abstract}

KEY WORDS: Sox, neurogenesis, Xenopus, neural tube

The Sox family of transcription factors belongs to the high mobility group (HMG) superfamily of proteins. Originally classified together on the basis of at least $50 \%$ identity to the HMG domain of SRY (Sox = Sry related HMG box) (Stevanovic et al., 1993), subsequent phylogenetic analysis revealed this basis too stringent (Bowles et al., 2000). Instead all Sox proteins share a common motif within the HMG domain, RPMNAFMVW, and cluster into 10 groups (A-J) (Bowles et al., 2000). While members across groups bear little resemblance outside of the HMG domain, members within groups are similar both within and outside of the HMG domain (Bowles et al., 2000). In addition to the HMG domain, the Sox group $B$ members also share a conserved group homology domain located just C-terminal to the HMG domain (Uchikawa et al., 1999, Bowles et al., 2000). The Sox group B has been further divided into two subgroups, B1 and B2, based on homology in the C-terminal domains (Uchikawa et al., 1999). Furthermore, SoxB1 proteins have been demonstrated to activate transcription of the $\delta 1$-crystallin enhancer whereas the SoxB2 proteins repress it (Uchikawa et al., 1999).

Sox proteins act in a wide range of developmental processes with the Group B proteins acting in the development of the nervous system. Specifically, SoxB1 proteins are generally thought to be involved in maintaining a neural stem cell or progenitor population. Functional analysis of chick Sox21 suggests that it specifically counteracts SoxB1 proteins, and as a consequence, promotes the progression of neurogenesis in the developing CNS
(Sandberg et al., 2005). Recent analysis knocking down the translation of Sox14 revealed disruption of hypothalamic patterning in zebrafish (Kurrasch et al., 2007).

Homologues of both Sox14 and Sox21 have been identified in chick (Rex et al., 1997) and mouse (Hargrave et al., 2000) with Sox21 also characterized in fish (De Martino et al., 1999). While Sox 21 is expressed broadly throughout the CNS in chick, mouse and zebrafish, with marked expression in the midbrain-hindbrain barrier, (Rex et al., 1997, De Martino et al., 1999, Uchikawa et al., 1999), Sox14 expression is limited to discrete domains in the nervous system in chick and mouse. In an effort to better understand the role and regulation of SoxB2 proteins during neurogenesis and to extend the phylogenetic analysis of the SoxB2 subgroup, we have cloned the $X$. laevisorthologs of sox14 and sox21 and report their spatiotemporal expression patterns.

\section{Isolation and sequence comparison of sox14 and sox21}

A $X$. laevisclone containing 160 bp of sequence with homology to the amino terminus of sox 14 was obtained in a screen for HMG containing homologs using a $X$. laevis genomic library. We used inverse PCR to clone the remainder of the coding region of a gene

Abbreviations used in this paper: AM, abducens motornucleus; DT, dorsal thalamus; HMG, high mobility group; OM, oculomotor motornucleus; OT, optic tectum; TM, trochlear motornucleus; WISH, whole mount in situ hybridization.

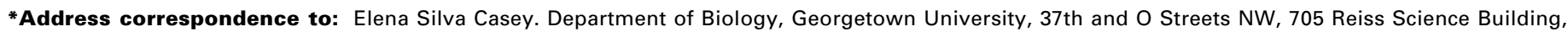
Washington DC, 20057, USA. Fax.: +1-202-687-4662. e-mail: emc26@georgetown.edu 
whose predicted amino acid sequence exhibits a high degree of conservation to orthologs of Sox14 (96\% amino acids are conserved with those in G. gallus, $94 \%$ in H. sapiensand M. musculus, and $97 \%$ in $X$. tropicalis) as determined using ClustalW (Fig. 1).

Because vertebrate Sox group $B$ genes do not contain introns (Bowles et al., 2000), we isolated $X$. laevis sox21 from genomic DNA using primers complementary to the 5' coding region and the 3' UTR of $X$. tropicalis sox21. We then employed inverse PCR to obtain the 5' coding region of $X$. laevis sox21 sequence. The predicted ORF encodes a 262 amino acid protein which is highly conserved with Sox21 proteins found in other vertebrates (Fig. 1, $90 \%$ amino acid conservation with G. gallus, $H$. sapiens and $M$. musculus, and $96 \%$ with $X$. tropicalis). As expected, a high degree of conservation to the HMG DNA binding domain and the group $B$ homology domain was seen for both Sox14 and Sox21 (Fig.1, blue and pink lines, respectively). In the carboxyl terminal domain of Sox21, notable features of conservation are the polyalanine stretches characteristic of these proteins (marked with ${ }^{*}$ in the Figure). Interestingly, while Sox21 proteins from human, mouse, chick and $X$. tropicalis have three polyalanine stretches, $X$. laevis lacks the last stretch (Fig. 1B), and analysis of Sox21 proteins from fish reveals that zebrafish and fugu have only the first polyalanine stretch (data not shown).

We generated a phylogenetic tree using parsimony analysis (PAUP* 4.0; Swofford et al., 2001). We used $X$. laevis Sox2 to root the tree, although we obtained similar results when the tree was rooted with either XISox1 or XISox3 (Fig. 2). Notably, the X. laevis SoxB2 proteins cluster with previously identified Sox14 or Sox21
A

XISox 14

$X$ tSox 14

HsSox14

MmSox14

GgSox14

XISox 14

XtSox 14

hsSox14

MmSox14

GgSox14

XISox14

XtSox14

HsSox14

MmSox14

GgSox14

\section{HMG domain}

1 MSKP VDH I KRPMNAFMWSRGQRRKMAQENPKMHNSE I SKRL GAEWKL LSE AEKRPY I DE AKRLRAQHMKEHPDYK YRPRRKPKNL L 87 1 MSKP VDH I KRPMNAFMWSRGQRRKMAQENPKMHNSE I SKRL GAEWK L LSE AEKRPY I DE AKRLRAQHMKEHPDYK YRPRRKPKNL L 87 1 MSKPSDH I KRPMNAFMWWRGQRRKMAQENPKMHNSE I SKRL GAEWKL LSE AEKRPY I DE AKRLRAQHMKEHPDYKYRPRRKPKNL L 87 1 MSKPSDH I KRPMNAFMWVRGQRRKMAQENPKMHNSE I SKRL GAEWKL LSE AEKRPY I DE AKRLRAQHMKEHPDYKYRPRRKPKNL L 87 1 MSKPSDH I KRPMNAFMWSRGQRRKMAQENPKMHNSE I SKRL GAEWKL LSE AEKRPY I DE AKRLRAQHMKEHPDYK YRPRRKPKNL L87

88 KKDRYVFPLPYFGDHDP LKT - GLSMSATDS I LGASEKARAFFPP TSTPYSLLDPSHFSSTTI QKMTEMPHTLATSTLPYASTL GYQN 173 88 KKDRYVFPLPYLGDHDPLKT - GLSMSATDS L LGASEKARAFLPPTSAPYSL LDPSQFSSTTI QKMTEMPHTLAASTLPYASTLGYQN 173 88 KKDRYVFPLPYLGDTDP LKAAGLPVGASDGL LSAPEKARAFLPPAS APYSLLDPAQFSSSAI QKMGE VPHTLATGALPYASTLGYQN 174 88 KKDRYVFPLPYLGDTDP LKAAGLPVGASDGL LSAPEKARAFLPPAS APYSLLDPAQFSSSA I QKMGE VPHTLATSALPYASTLGYQN 174 88 KKDRYVFPLPYLGETDPLKAAGLPVGATDSL LSSPEKARAFLPPTSAPYSL LDPSQFSSSA I QKMTE VPHTLATGTLPYASTLGYQN 174

174 GAFGGLSCPSQHTHTHPSPTNPGYVVPCNCTAWS ASNLQPPVAY I LFPGMTKAG I DPYSSAHTTAM 174 GAFGGLSCPSQHTHTHPSPTNPGYVVPCNCSAWSASNLQPPVAY I LFPGMTKAGLDPYSSAHTAAM 175 GAFGSLSCPSQHTHTHPSPTNPGYVVPCNCTAWSASTLQPPVAY I LFPGMTKTG IDPYSSAHATAM 175 GAFGS LSCPSQHTHTHPSP TNPGYVVPCNCTAWS AS TLQPP VAY I LFPGMTK TG I DPYSSAHATAM 175 GAFGSLSCPSQHTHTHPSP TNPGYVVPCNCTAWS ASSLQPPVAY I LFPGMTKTG I DPYSSAHATAM

\section{B}

\section{HMG domain}

XISox 21 1 MAKP VDHVKRPMNAFMWSRAQRRKMAQENPKMHNSE I SKRL GAEWKL L TE AEKRPF I DE AKRLRAMHMKEHPDYKYRPRRKPK TL L 87 1 MSKP VDHVKRPMNAFMWWSRAQRKMAQENPKMHNSE I SKRL GAEWKL L TESEKRPF I DE AKRLRAMHMKEHPDYKYRPRRKPK TL L 87 1 MSKP VDHVKRPMNAFMWWRAQRRKMAQENPKMHNSE I SKRL GAEWKL L TESEKRP F I DE AKRLRAMHMKEHPDYKYRPRRKPK TL L 87 1 MSKP VDHVKRPMNAFMWSRAQRRKMAQENPKMHNSE I SKRL GAEWKL LSEAEKRPF I DE AKRLRAMHMKEHPDYKYRPRRKPK TLL 87

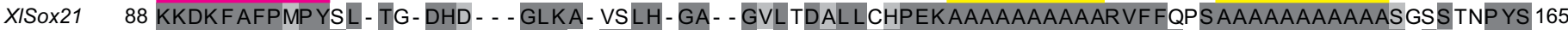

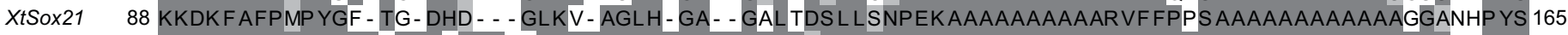

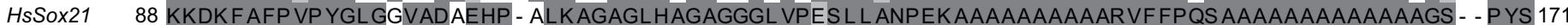

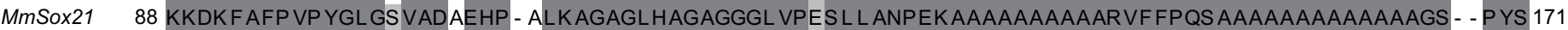

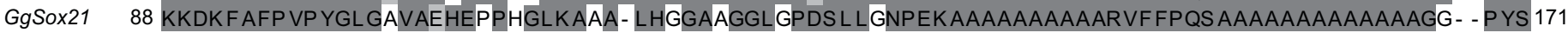

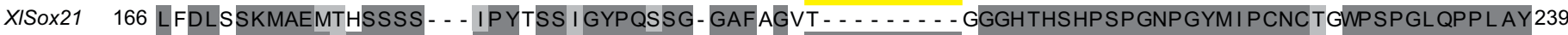

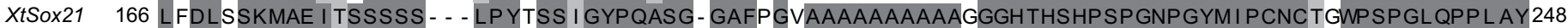

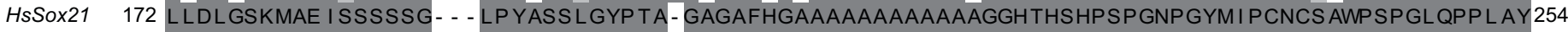

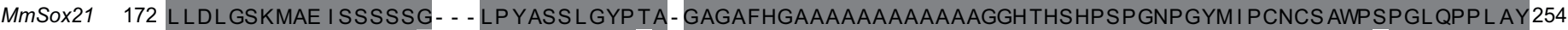

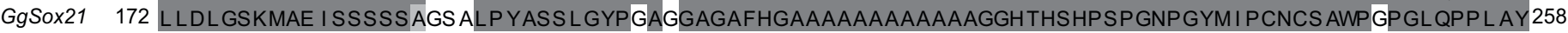

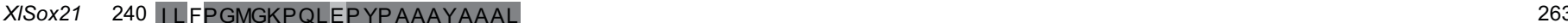

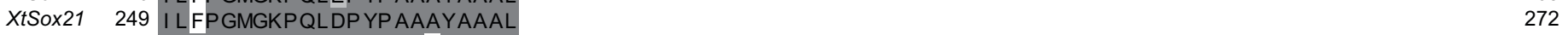

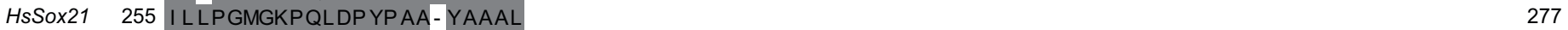

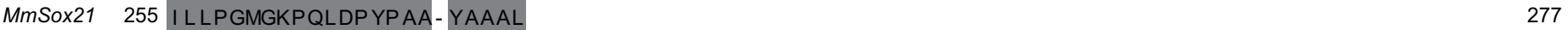

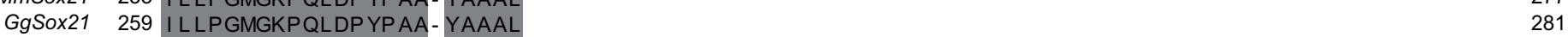

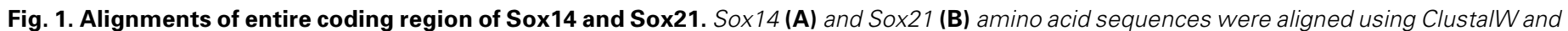

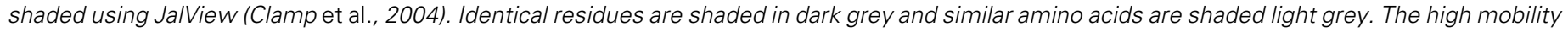

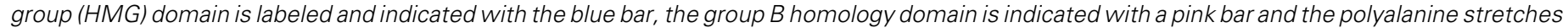

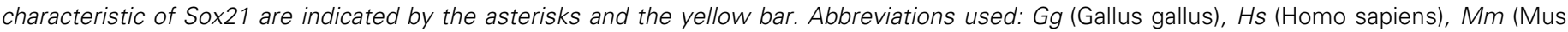
musculus), Xt (Xenopus tropicalis), and XI (Xenopus laevis). 


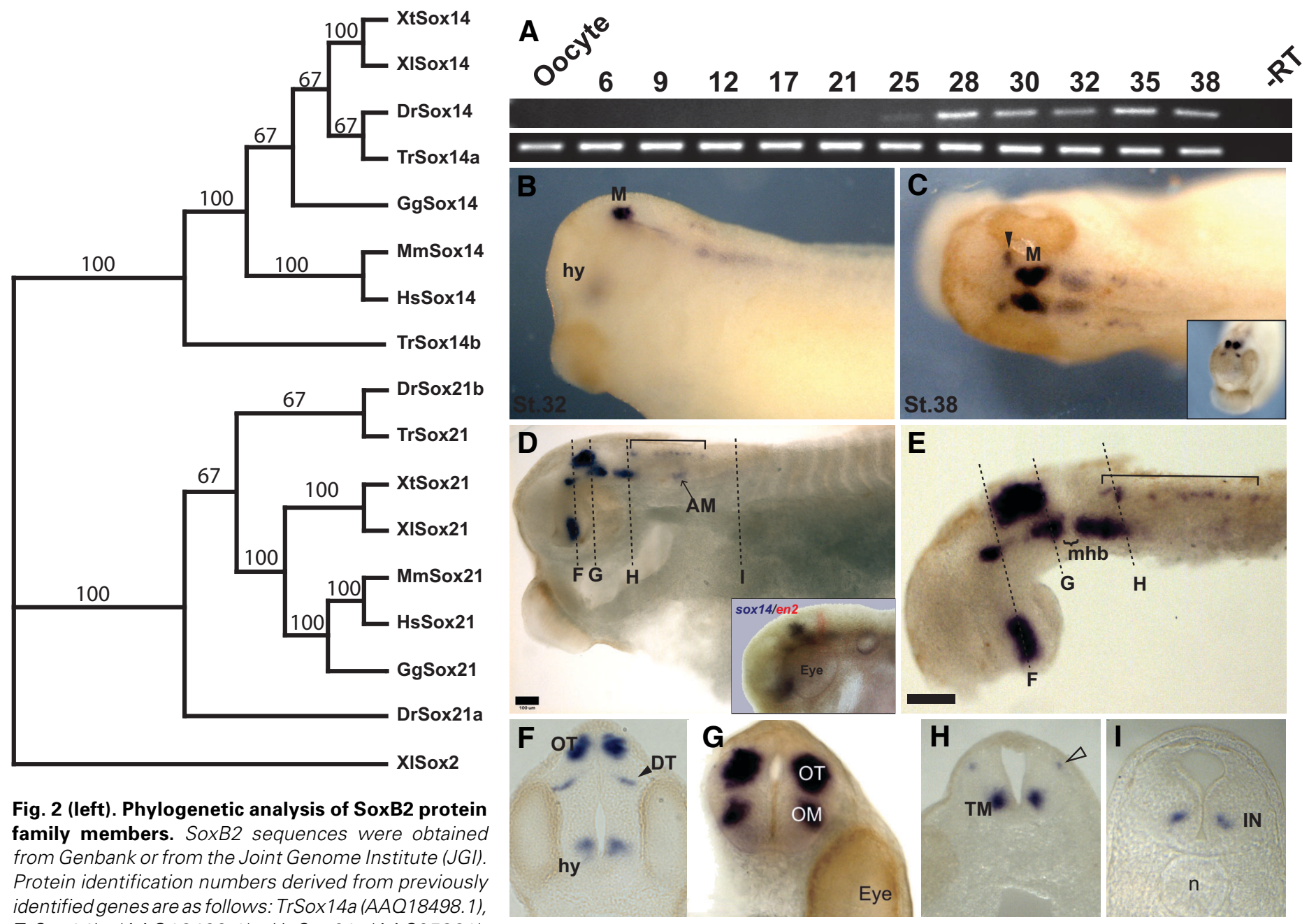
(A) follows: TrSox14a (AAO18498.1), TrSox14b (AAQ18499.1), HsSox21 (AAC95381), GgSox21 (BAA77266.1), MmSox21 (AAN6055.1), DrSox21a (NP_571361), DrSox21B (NP_001009888.1), HsSox14 (NP_004180.1), GgSox14(NP_990092.1), MmSox14 (AAl00556), TrSox14a(AAQ18498.1), DrSox14 (AA108034) and TrSox14b (AAQ18499.1). Sequences obtained from JGl are as follows: XtSox21 (gw1.467.21) and XtSox14 (e_gw1.344.69.1). Gg (Gallus gallus), Hs (Homo sapiens), Mm (Mus musculus), Dr (Danio rerio), $\operatorname{Tr}$ (Takifugu rubripes).

Fig. 3 (right). Spatio-temporal expression pattern of sox14. (A) RT-PCR analysis from oocytes and embryos to stage 38 as indicated across the top. ODC (lower panel) was used as the loading control. (B-I) In situ hybridization of sox14 at indicated stages. In all figures, anterior is to the left. (B) Lateral view; (C) dorsal view, anterior view in the inset. (D) Sagittal sections of stage 38, double in situ of sox14 and en2 in the inset. (E) Dissected brain from stage 38 embryo. (F-I) Transverse sections from stage 32 (I) and 38 (F-H) embryos. Symbols: bracket, expression in vestibular nuclei; black arrowhead, dorsal thalamus; open arrowhead, dorsal hindbrain sox14 positive cells; $M$, midbrain; hy, hypothalamus; and AM, abducens motornucleus; mhb, midbrain hindbrain barrier; OT, optic tectum; DT, dorsal thalamus; OM, oculomotor motornucleus; TM, trochlear motornucleus; IN, interneurons. Black bar equivalent to $100 \mu \mathrm{m}$.

proteins, showing closest conservation with $X$. tropicalis. In addition, the indicated bootstrap values provide strong support for the clustering. We also constructed a tree using the distance neighborjoining method (data not shown) and obtained the same results.

\section{Sox14 spatio-temporal expression}

To determine the temporal and spatial expression of $X$. laevis sox 14, we performed RT-PCR and whole mount in situhybridization (WISH) at a variety of embryonic stages. By RT-PCR analysis, sox 14 expression is first detectable at stage 25 , peaks at stage 28 and this level of expression persists throughout all later stages examined (to st. 38, Fig. 3A). Using WISH we examined the spatial expression pattern of sox 14 from stages 17 through stage 48 . Sox 14 is expressed by stage 28 (data not shown), with expression in the midbrain and hypothalamus clearly detectable by stage 32 , as well as a faint ventral expression domain caudal to the midbrain (Fig. 3B). While expression remains strongest in the presumptive midbrain, by stage 38 additional discrete expression domains became apparent (Fig. 3C, arrowheads). In sagittal sections and dissected brains from stage 38 stage embryos, it is evident that sox 14 is expressed in the hypothalamus, the midbrain and the hindbrain (Fig. 3D and E). Within the midbrain, there are two expression domains: one dorsal domain, the optic tectum (OT), and one ventral domain, likely to be within the oculomotor 
motornucleus (OM) (Fig. 3D, E and G). Caudal to the oculomotor motornucleus are sox14 expressing-cells likely to be the trochlear motornucleus (TM) and even further caudal are the faintly labeled cells in the region of the abducens motornucleus (AM) (Fig. 3D) (Hartenstein, 1993, Guo et al., 1999,Talikka et al., 2004). To confirm the colocalization of the somatic motornuclei with sox14 expression, we performed double in situhybridization with sox 14 and en2 (inset, Fig. 3D) or pax2 (data not shown), markers of the midbrain-hindbrain boundary. The sox 14 expression overlaps with the ocular motonucleus which is directly rostral to the MHB and the trochlear motornucleus just caudal to the MHB. In the dorsal hindbrain are single sox 14 positive cells dispersed though the
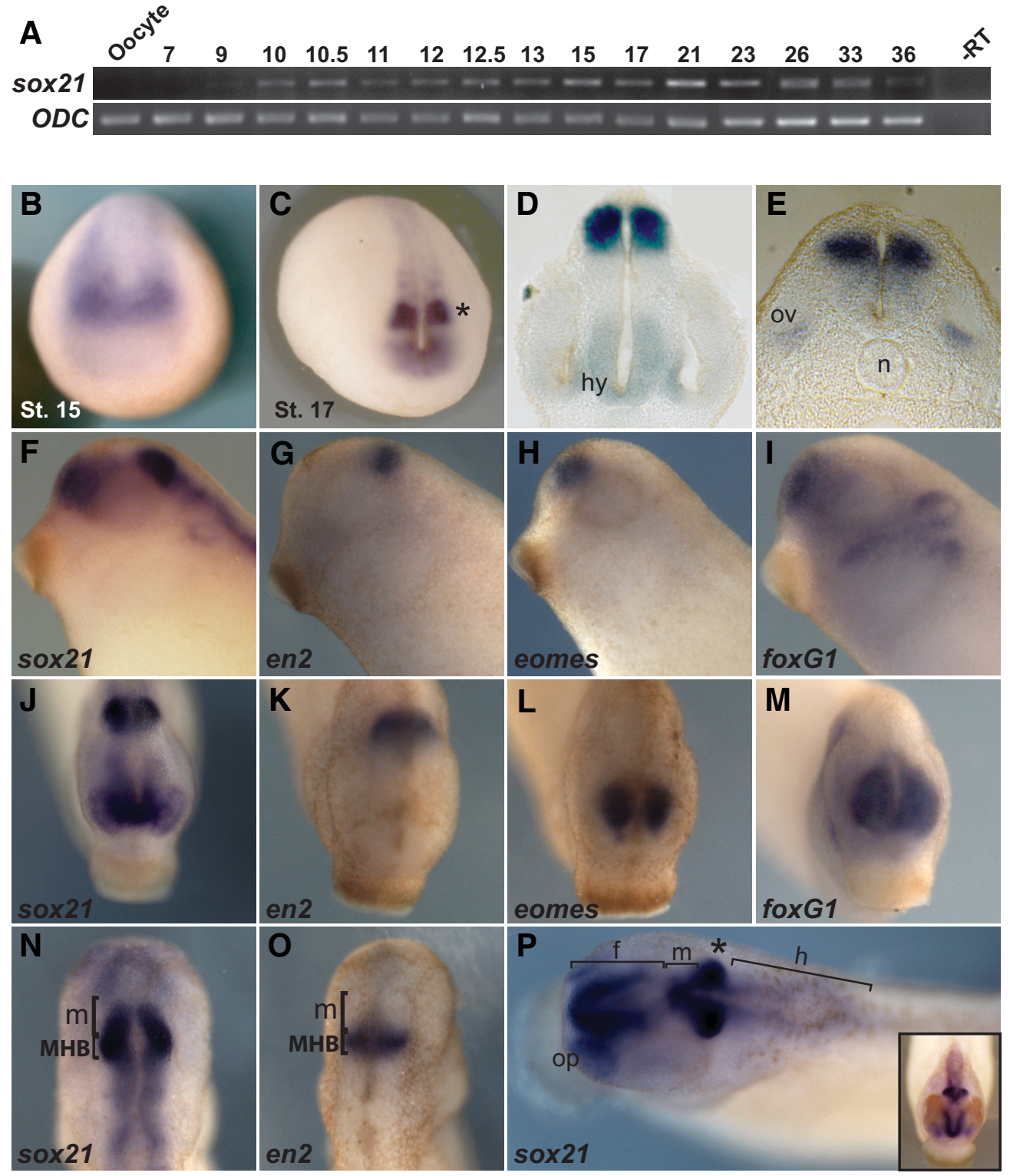

Fig. 4. Spatio-temporal expression pattern of sox21. (A) RT-PCR analysis of embryos from oocyte to stage 36 as indicated across the top. ODC was used as the loading control. (B, C, F, J, N, P) In situ hybridization of embryos stained for sox21 at indicated stages and (F-M, 0) for regional brain markers as indicated. (B,C, J-M, inset P) Anterior views. (N-P) Dorsal views. (F-I) Lateral views. (D,E) Transverse sections generated from a stage 31 embryo. Symbols: Black asterisks, midbrain-hindbrain boundary; $f$, forebrain; $h$, hindbrain; $m$, midbrain; hy, hypothalamus; $n$, notochord; op, olfactory placode; ov, otic vesicle.
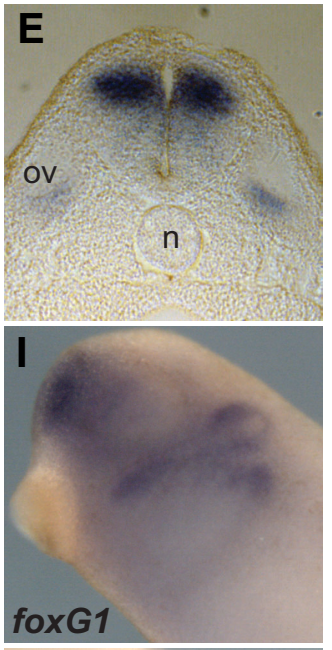

vestibular nuclear complex (Fig 3D and E, bracket). Anterior to the midbrain expression is a small expression domain, likely to be the (Fig. 3C-F) (Bachy etal., 2001). In transverse omain of the spinal cord as early as stage 32 (Fig. 31 and cord marked by sox 14 corresponds to the subset of interneurons marked by mouse and chick SOX14 (Uchikawa et al., 1999,

\section{Sox21 spatio-temporal expression}

We examined the temporal expression pattern of sox21 during Xenopus embryo development using RT-PCR. Expression was absent from the oocyte and stages prior to the midblastula transition (st. 8), first detected at stage 10 and maintained in all subsequent stages examined (to st. 36, Fig. 4A). Using whole-mount in situ hybridization, sox21expression was first detected at stage 15 throughout the anterior neural plate (Fig. 4B). By stage 17, sox21 expression was still throughout the presumptive CNS; however, a noticeable gap in expression was observed (Fig. 4C). The region immediately posterior to this gap had a considerably higher level of expression than neighboring regions (Fig. $4 \mathrm{C}$, black asterisk). This restricted pattern of expression persisted through late tailbud with expression strongly detected in the presumptive forebrain, olfactory placode, and otic vesicle by stage 33 (Fig. 4 E,P). To identify the expression domains of sox21, we compared its expression to that of other well characterized brain markers, en2, which marks the midbrain-hindbrain boundary (Hemmati-Brivanlou et al., 1991), eomes, which marks the telencephaIon and a portion of the diencephaIon (Bachy et al., 2002) and foxG1(formerly known as $b f-1$ ), which also marks the telencephalon(Regad et al., 2007) (Fig. 4 F-O). As labeled in Fig. 4P, we determine that sox21 is expressed throughout the central nervous system, with strong expression in the forebrain, midbrain, and $\mathrm{MHB}$ and reduced expression in a region of the diencephalon.

To determine the dorsoventral expression pattern in the developing brain and spinal cord, we analyzed transverse sections of stained embryos (Fig. 4D and E). At stage 31, 
sox21 expression was detected in the forebrain and hypothalamus (Fig. 4D), in the dorsal region of the hindbrain and developing neural tube, and weakly in the otic vesicles (Fig. 4E and data not shown).

In summary, we have shown that $X$. laevis has at least two soxB2genes, sox 14 and sox21. They have patterns of expression distinct from each other throughout stages of early development. Here we show sox 14 marks a subset of interneurons located in the ventral portion of the spinal cord as well as in a portion of the dorsal thalamus. Except for the hypothalamus, all other sox 14 labeled cells and nuclei are directly or indirectly involved in eye movement through optokinetic and vestibular reflexes (Nieuwenhuys et al., 1998). Cell cycle exit data suggest that most of the labeled cells are postmitoic neurons that have exited the cell cycle between st. 23-30 (Hartenstein, 1993). Interestingly, the onset of expression of sox14 correlates with the onset of neuronal differentiation of the ventral midbrain and ventral interneurons of the spinal in Xenopus laevis (Hartenstein, 1993). Combined these data may suggest that Sox14 is a master regulator for eye movement centers as much as Atoh1 is governing development of proprioreceptive centers (Bermingham et al., 2001). Indubitably, experimental evidence is needed to verify this suggestion. X. laevis sox21 expression marks the olfactory placodes, forebrain, midbrainhindbrain barrier, and neural tube, with a gap of expression corresponding to the dorsal thalamus. It will be interesting to investigate the roles these genes have in neurogenesis and patterning in $X$. laevis.

\section{Experimental Procedures}

\section{Cloning and sequence analysis}

Sox14: Using a probe designed to be complementary to the HMG domain of Sox genes, a $X$. laevis genomic library was screened. One clone contained $1218 \mathrm{bp}$ upstream of the predicted start ATG and 160 bp downstream. We used the sequence downstream of the predicted ATG to BLAST all known EST databases and found that it that was highly homologous to sox 14 genes. Using inverse PCR we obtained a 720 bp product and corresponded with the ORF for Sox 14 . This product was cloned into the pGEM T-easy vector (Promega) to generate pGEM-XIsox14.Primers used for the inverse PCR were:

F1: 5'TATGACAGTTGGAGAGGGC 3',

R1: 5' GGGAGCATGTGGGTAGTCT 3',

F2: 5' TATGACAGTTGGAGAGGGC 3',

R2: 5' CATAGACCTGGAGAGTAATTG 3'.

sox21: The following primers were designed based on the sequence of sox21found in the $X$. tropicalisgenome v4.1 (http://genome.jgi-psf.org/ Xentr4/Xentr4.home.html): F 5' ATGGCTAAACCGGTGGATC 3' R: 5' GCCAGTGCCCTTAGTCGG 3'. The amplified 789 bp product was cloned into pGEM T-easy vector (Promega) to generate pGEM-XIsox21.

We used the sequence information from pGEM-Sox21 to generate inverse PCR primers to obtain the $X /$ SoX21 sequence:

F1: 5' CTGGGTGACACAGCAAGGCG 3';

R1: 5' GGCAGAGATGACACATTC 3';

F2: 5' CATGTAAACTAACAGCCTTC 3';

R2: 5' CATCTATTCCTTATACCTCG 3'.

\section{Protein alignment and tree construction}

Amino acid sequences were aligned using ClustalX, available from $\mathrm{ftp}$ ://ftp-igbmc.u-strasbg.fr/pub/ClustalX/. The alignment was color coded according to Blosum62 scores using JalView (Clamp et al., 2004). The parsimony tree and neighbor-joining distance tree were constructed using PAUP4.0*.

\section{Semi-quantitative $R T$-PCR analysis}

RNA was extracted for RT-PCR analysis as described (Wilson and Melton, 1994). One embryo equivalent was used for each RT-PCR experiment. To assay for DNA contamination in RT-PCR experiments, an embryo was processed without reverse transcriptase and labeled as the RT minus lane in each experiment. Ornithine decarboxylase (ODC) was used as the loading control. RT-PCR primers for the ODC have been described elsewhere (Hudson et al., 1997). The primers used for detection of Xenopus soXB2 genes are:

sox21: U, 5'-TAGTTTGACAGGGGACCATGATGGG-3';

D, 5'-CCCCACCTGTAACCCCAGCAAA-3'; $64^{\circ} \mathrm{C}, 25$ cycles.

sox 14: U, 5' CTTTCCACCAACATCAACAC 3';

D, 5' CCAGCTTTAGTCATACCAGG 3'; 55 $\mathrm{C}, 30$ cycles.

\section{Whole-mount in situ hybridization}

Whole-mount in situ hybridizations were performed as described previously (Harland, 1991). Antisense RNA DIG labeled (Roche) probes were synthesized using either pGEM-XLsox14 or pGEM-XLsox21 and detected using BM purple (Roche). Double in situ hybridization were performed as described previously (Hollemann et al., 1998), DIG labeled sox14 and fluorescein labeled (Roche) en2 and pax2 probes were employed.

\section{Acknowledgements}

We thank Silvia Brunelli for the genomic clone containing a portion of Sox 14 and Peter Armbruster and all members of the Casey Laboratory for discussions and comments on the manuscript. Funding for D.C. was provided by the NIH NSO4918 (to E.S.C.).

\section{References}

BACHY, I., BERTHON, J. and RETAUX, S. (2002). Defining pallial and subpallial divisions in the developing Xenopus forebrain. Mech Dev 117: 163-72.

BACHY, I., VERNIER, P. and RETAUX, S. (2001). The LIM-homeodomain gene family in the developing Xenopus brain: conservation and divergences with the mouse related to the evolution of the forebrain. J Neurosci21: 7620-9.

BERMINGHAM, N.A., HASSAN, B.A., WANG, V.Y., FERNANDEZ, M., BANFI, S., BELLEN, H.J., FRITZSCH, B. and ZOGHBI, H.Y. (2001). Proprioceptor pathway development is dependent on Math1. Neuron 30: 411-22.

BOWLES, J., SCHEPERS, G. and KOOPMAN, P. (2000). Phylogeny of the SOX family of developmental transcription factors based on sequence and structural indicators. Dev Bio/227: 239-55.

CLAMP, M., CUFF, J., SEARLE, S.M. and BARTON, G.J. (2004). The Jalview Java alignment editor. Bioinformatics 20: 426-7.

DE MARTINO, S.P., ERRINGTON, F., ASHWORTH, A., JOWETT, T. and AUSTIN, C.A. (1999). sox30: a novel zebrafish sox gene expressed in a restricted manner at the midbrain-hindbrain boundary during neurogenesis. Dev Genes Evo/209: 357-62.

GUO, S., BRUSH, J., TERAOKA, H., GODDARD, A., WILSON, S.W., MULLINS, M.C. and ROSENTHAL, A. (1999). Development of noradrenergic neurons in the zebrafish hindbrain requires BMP, FGF8, and the homeodomain protein soulless/Phox2a. Neuron 24: 555-66.

HARGRAVE, M., KARUNARATNE, A., COX, L., WOOD, S., KOOPMAN, P. and YAMADA, T. (2000). The HMG box transcription factor gene Sox14 marks a novel subset of ventral interneurons and is regulated by sonic hedgehog. Dev Biol219: 142-53.

HARLAND, R.M. (1991). In situ hybridization: an improved whole-mount method for Xenopus embryos. Methods Cell Bio/36: 685-95.

HARTENSTEIN, V. (1993). Early pattern of neuronal differentiation in the Xenopus embryonic brainstem and spinal cord. J Comp Neuro/328: 213-31.

HEMMATI-BRIVANLOU, A., DE LA TORRE, J.R., HOLT, C. and HARLAND, R.M. (1991). Cephalic expression and molecular characterization of Xenopus En-2. Development 111: 715-24. 
HOLLEMANN, T., BELLEFROID, E. and PIELER, T. (1998). The Xenopus homologue of the Drosophila gene tailless has a function in early eye development. Development 125: 2425-32.

KURRASCH, D.M., CHEUNG, C.C., LEE, F.Y., TRAN, P.V., HATA, K. and INGRAHAM, H.A. (2007). The neonatal ventromedial hypothalamus transcriptome reveals novel markers with spatially distinct patterning. JNeurosCi 27: 13624-34.

NIEUWENHUYS, R., DONKELAAR, H.J.T. and NICHOLSON, C. (1998). The central nervous system of vertebrates. Berlin; New York: Springer.

REGAD, T., ROTH, M., BREDENKAMP, N., ILLING, N. and PAPALOPULU, N. (2007). The neural progenitor-specifying activity of FoxG1 is antagonistically regulated by CKI and FGF. Nat Cell Bio/9: 531-40.

REX, M., UWANOGHO, D.A., ORME, A., SCOTTING, P.J. and SHARPE, P.T. (1997). cSox21 exhibits a complex and dynamic pattern of transcription during embryonic development of the chick central nervous system. Mech Dev66: 3953.

SANDBERG, M., KALLSTROM, M. and MUHR, J. (2005). Sox21 promotes the progression of vertebrate neurogenesis. Nat Neurosci 8: 995-1001.
STEVANOVIC, M., LOVELL-BADGE, R., COLLIGNON, J. and GOODFELLOW, P.N. (1993). SOX3 is an X-linked gene related to SRY. Hum Mol Genet2: 20138.

SWOFFORD, D.L., WADDELL, P.J., HUELSENBECK, J.P., FOSTER, P.G., LEWIS, P.O. and ROGERS, J.S. (2001). Bias in phylogenetic estimation and its relevance to the choice between parsimony and likelihood methods. Syst Biol 50: 525-39.

TALIKKA, M., STEFANI, G., BRIVANLOU, A.H. and ZIMMERMAN, K. (2004). Characterization of Xenopus Phox2a and Phox $2 b$ defines expression domains within the embryonic nervous system and early heart field. Gene Expr Patterns 4: 601-7.

UCHIKAWA, M., KAMACHI, Y. and KONDOH, H. (1999). Two distinct subgroups of Group B Sox genes for transcriptional activators and repressors: their expression during embryonic organogenesis of the chicken. Mech Dev84: 10320.

WILSON, P.A. and MELTON, D.A. (1994). Mesodermal patterning by an inducer gradient depends on secondary cell-cell communication. Curr Bio/4: 676-86. 


\section{Further Related Reading, published previously in the Int. J. Dev. Biol.}

See our recent Special Issue Ear Development edited by Bernd Fritzsch and Fernando Giraldez at:

http://www.ijdb.ehu.es/web/contents.php?vol=51\&issue=6-7

Loss of Sox 9 function results in defective chondrocyte differentiation of mouse embryonic stem cells in vitro Gunnar Hargus, Ralf Kist, Jan Kramer, Daniela Gerstel, Angela Neitz, Gerd Scherer and Jürgen Rohwedel

Int. J. Dev. Biol. (2008) 52: 323-332

Spatiotemporal clustering of cell death in the avian forebrain proliferative zone

Christine J. Charvet and Georg F. Striedter

Int. J. Dev. Biol. (2008) 52: 345-352

Expression of protocadherin 18 in the CNS and pharyngeal arches of zebrafish embryos

Fumitaka Kubota, Tohru Murakami, Yuki Tajika and Hiroshi Yorifuji

Int. J. Dev. Biol. (2008) 52: 397-405

Expression of Shisa2, a modulator of both Wnt and Fgf signaling, in the chick embryo

Thomas A. Hedge and Ivor Mason

Int. J. Dev. Biol. (2008) 52: 81-85

A network of growth and transcription factors controls neuronal differentation and survival in the developing ear Hortensia Sánchez-Calderón, Marta Milo, Yolanda León and Isabel Varela-Nieto

Int. J. Dev. Biol. (2007) 51: 557-570

Expression and regulation of Xenopus CRMP-4 in the developing nervous system Jacob Souopgui, Tiemo J. Klisch, Tomas Pieler and Kristine A. Henningfeld

Int. J. Dev. Biol. (2007) 51: 339-343

$\mathrm{XSu}(\mathrm{H}) 2$ is an essential factor for gene expression and morphogenesis of the Xenopus gastrula embryo Motoaki Ito, Tomohisa Katada, Seiji Miyatani and Tsutomu Kinoshita

Int. J. Dev. Biol. (2007) 51: 27-36

Expression and functions of FGF ligands during early otic development

Thomas Schimmang

Int. J. Dev. Biol. (2007) 51: 473-481

Soluble membrane-type 3 matrix metalloprioteinase causes changes in gene expression and increased gelatinase activity during Xenopus laevis development Logan A. Walsh, Colin A. Cooper and Sashko Damjanovski

Int. J. Dev. Biol. (2007) 51: 389-396

Interplay of Pax6 and SOX2 in lens development as a paradigm of genetic switch mechanisms for cell differentiation

Hisato Kondoh, Masanori Uchikawa and Yusuke Kamachi

Int. J. Dev. Biol. (2004) 48: 819-827

Sox9, a novel pancreatic marker in Xenopus.

Young-Hoon Lee and Jean-Pierre Saint-Jeannet

Int. J. Dev. Biol. (2003) 47: 459-462

Roles of Sox factors in neural determination: conserved signaling in evolution? Y Sasai

Int. J. Dev. Biol. (2001) 45: 321-326

Characterization and early embryonic expression of a neural specific transcription factor $\mathrm{xSOX} 3$ in Xenopus laevis.

R Penzel, R Oschwald, Y Chen, L Tacke and H Grunz

Int. J. Dev. Biol. (1997) 41: 667-677

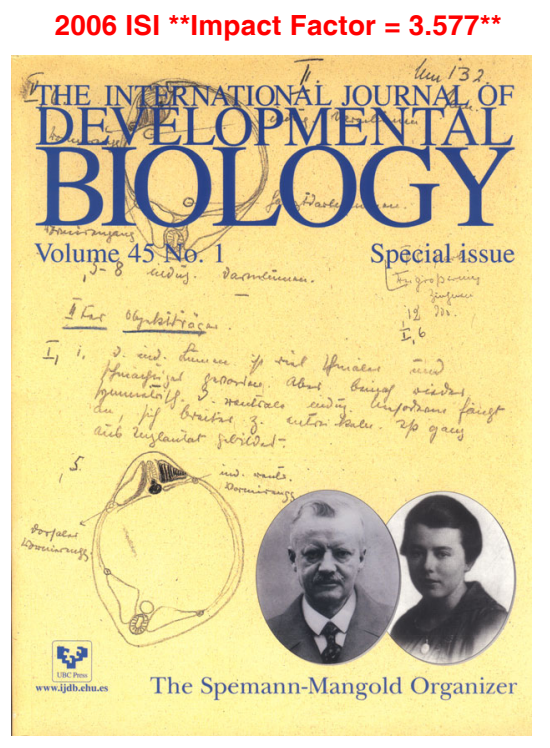

